\section{Caracterização do consumo de maconha entre escolares do ensino médio de São José do Rio Preto, SP, Brasil, 2003}

\section{Marijuana consumption among high school students in São José do Rio Preto, State of São Paulo, Brazil, 2003}

\section{Rafael Augusto Borges Pavani ${ }^{1}$ \\ Elissandro de Freitas Silva' \\ Maria Silvia de Moraes ${ }^{2}$ \\ Francisco Chiaravalloti Neto ${ }^{2,3}$}

'Graduandos em Medicina, Faculdade de Medicina de São José do Rio Preto, SP ${ }^{2}$ Departamento de Epidemiologia e Saúde Coletiva, Faculdade de Medicina de São José do Rio Preto, SP

${ }^{3}$ Superintendência de Controle de Endemias, São José do Rio Preto, Brasil

Financiamento: Bolsa de Iniciação Científica - BIC, FAMERP, processo número 3287/2004 Correspondência: Rafael Augusto Borges Pavani, Departamento de Epidemiologia e Saúde Coletiva, Faculdade de Medicina de São José do Rio Preto. Av. Brigadeiro Faria Lima 5416, São José do Rio Preto, SP, 15090-000, Brasil. E-mail:rafael_pavani@universia.com.br

\section{Resumo}

Objetivo: Caracterizar o consumo de maconha entre escolares do ensino médio do município de São José do Rio Preto - SP. Método: Utilizou-se um estudo de corte transversal em escolas públicas do ensino médio com uma amostragem de conglomerados. Foram aplicados 1.041 questionários autopreenchíveis de maneira coletiva nas classes, mantidos sem identificação. As variáveis selecionadas foram cruzadas e para a associação foi realizado o teste do qui-quadrado com nível de significância de 5\%. Resultados: As prevalências do consumo de maconha foram: uso na vida, $12,1 \%$; no ano, $7,4 \%$; no mês, $4,1 \%$; e na semana, $2,9 \%$. O consumo de maconha na vida foi mais prevalente no sexo masculino, período escolar noturno, estado civil casado, não ter ou não praticar religião e não morar com pai e/ou mãe. Relacionamento bom com os pais e os pais viverem juntos com bom relacionamento estavam associados a menor consumo de maconha. Dentre as atividades de lazer, aqueles que experimentaram maconha referiram mais sair sem destino certo, ir dançar, freqüentar bares e ficar com namorado(a), e menos assistir televisão, sair com a família e ir ao cinema. Ingerir bebida alcoólica toda semana e usar tabaco estiveram associados a um maior índice de experiência com maconha. Experimentar maconha relacionou-se com maiores índices de experiência com anfetamínicos, alucinógenos, cocaína e crack. Conclusão: O consumo de maconha está relacionado a muitas variáveis. Família e religiosidade estão associadas a menor consumo de maconha, enquanto desajuste familiar e uso de álcool e tabaco estão associados a maiores índices de consumo da droga.

Palavras-chave: Consumo de maconha. Estudantes. Epidemiologia. Família. Drogas ilícitas. Transtornos relacionados ao uso de substâncias. 
Abstract

Objective: This research aimed to study marijuana consumption among high school students in São José do Rio Preto, SP, Southeastern Brazil. Method: A crosssectional survey was carried out in São José do Rio Preto. A self-completion questionnaire was given to a proportional sample of 1,041 teenagers enrolled in the $9^{\text {th, }} 10^{\text {th }}$ and $11^{\text {th }}$ grades of public schools. Results: The prevalence of marijuana consumption was: throughout life: $12.1 \%$, in the past year: $7.4 \%$, in the past month: $4.1 \%$, and in the past week: $2.9 \%$. Marijuana consumption was more prevalent in male, nighttime students, married individuals, those who work, those who do not have a religion or do not practice it, and who does not live with a father and/or mother. Excellent or good relationship with parents and parents living together with a good relationship were associated with less prevalent marijuana consumption. Students that experimented marijuana referred activities like wandering, going dancing, attending bars, and staying with boyfriend / girlfriend more frequently as leisure activities, and referred watching TV, going out with family and going to the movies less frequently than the population in general. Weekly alcohol consumption and tobacco use were associated with higher marijuana experience indices. Marijuana experience is associated with greater amphetamine, hallucinogen, cocaine, and crack experience indices. Conclusion: Marijuana consumption is associated with many variables. Family and religiosity may be protective factors against the marijuana experience, while family disharmony, tobacco and weekly alcohol use were associated with higher marijuana consumption indices.

Keywords: Consumption of marijuana. Students. Epidemiology. Family. Illicit drugs. Substance-related disorders.

\section{Introdução}

Nos últimos anos, muitos estudos têm demonstrado um índice elevado para o uso abusivo de drogas lícitas e ilícitas entre os adolescentes ${ }^{1-6}$. No período de 14 a 16 anos de idade, encontra-se o maior índice de início do consumo de drogas ilícitas e de tabaco ${ }^{1,2}$, demonstrando a importância da fase de adolescência na questão das drogas $^{7}$. Nesta fase há rápido desenvolvimento biopsicossocial, e as dificuldades na resolução do processo podem influenciar pelo resto da vida ${ }^{8}$.

No Brasil, segundo a literatura, há índices significativos de usuários de drogas nas escolas ${ }^{2,5,9,10}$. Dentre as drogas ilícitas, a maconha é uma das mais experimentadas e utilizadas com maior freqüência por adolescentes no Brasil e também em outros países, como Chile, México, Estados Unidos, Noruega e Croácia, e na América Central ${ }^{3,6,11-15}$

O consumo de maconha é um problema de saúde pública difícil de ser controlado, pois se associa às características próprias da adolescência, na qual surgem conflitos com os pais e a sociedade, busca por liberdade individual e desejo por novas experiências ${ }^{7,8,16}$. Essa droga é freqüentemente considerada pelos jovens menos maléfica do que outras drogas ilícitas ou mesmo lícitas, e mais aceita socialmente, mesmo com o reconhecimento dos comprometimentos familiares, sociais e biológicos resultantes do uso contínuo $0^{7,16-18}$

Segundo o I Levantamento Domiciliar Nacional Sobre o Uso de Drogas Psicotrópicas realizado pelo CEBRID, a maconha é a droga ilícita mais consumida no Brasil. Estudos mostram, no Brasil, o índice de uso de cannabis na vida entre escolares variando de 6,6 a $19,9 \%$, com a idade da primeira experiência concentrada na faixa de 14 a 16 anos $^{1,3,10,19}$. O uso na semana ou uso freqüente ficou entre 0,9 e $4,4 \%^{1,2,4,9}$. Essa droga é utilizada por todas as classes sociais em níveis elevados, quando comparada com as outras drogas ilícitas ${ }^{7,9,20,21}$.

Alguns dos fatores relatados, relaciona- 
dos ao consumo de maconha, foram: disponibilidade financeira, disponibilidade da droga, tolerância social, uso de drogas entre amigos ou na família, depressão, problemas familiares, estudo em período noturno, relacionamento ruim com quem mora, uso de tabaco, consumo semanal de álcool, comportamentos de risco e delinqüência, comportamento sexual de risco, maior taxa de faltas à escola, maior número de reprovações escolares, não trabalhar,

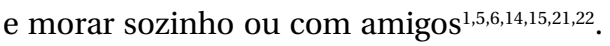

Assim como o tabagismo e o etilismo estão associados ao consumo de maconha, a experiência com essa droga é por vezes considerada a "porta de entrada" para drogas mais pesadas, como cocaína, alucinógenos e crack $^{16-18}$. Sanchez e Nappo (2002) entrevistaram 31 usuários ou ex-usuários de crack em um estudo qualitativo para saber a seqüência de drogas utilizadas por eles. O estudo indicou uma primeira fase de uso pesado de drogas lícitas (álcool e tabaco) em idade precoce, seguida por uma segunda fase com consumo de maconha, iniciado geralmente entre 12 e 16 anos de idade. Todos os entrevistados referiram ter utilizado maconha antes de começarem drogas mais pesadas como cocaína, alucinógenos e crack (apenas um referiu utilizar primeiro chá alucinógeno e depois maconha). A maconha foi considerada por eles uma droga "leve" e sem capacidade de dependência, e a progressão para drogas mais pesadas decorreu da busca por maior prazer $^{17}$.

Em 2003 foi realizada uma pesquisa em São José do Rio Preto - SP envolvendo 1.035 escolares do ensino médio, resultando em uma caracterização da prevalência do consumo de substâncias psicoativas semelhante à encontrada em outros estudos ${ }^{23}$. Nessa pesquisa obtiveram-se dados referentes ao consumo de maconha e outras drogas, vida familiar dos alunos, religião, trabalho, escolaridade dos pais, atividades de lazer, entre outros, que em uma análise preliminar encontrou freqüência de uso de maconha de $12,1 \%$ na vida, $7,4 \%$ no ano, $4,1 \%$ no mês e $2,9 \%$ na semana ${ }^{23}$.
O presente estudo tem como objetivo geral caracterizar a população de usuários de maconha das escolas públicas do ensino médio de São José do Rio Preto, SP, Brasil, através dos dados obtidos na pesquisa de $2003^{23}$. Serão analisadas variáveis socioeconômicas, o relacionamento familiar, atividades de lazer e consumo de outras drogas, visando além da caracterização, o delineamento de possíveis fatores protetores ou de risco para o consumo de maconha.

\section{Metodologia}

\section{Área de estudo, população alvo}

A cidade de São José do Rio Preto localiza-se na região sudeste do Brasil, no Estado de São Paulo, e dista 442 km, em sentido noroeste, da capital. A população estimada para o ano de 2003 era de 382.273 habitantes $^{24}$. O universo amostral constituiu-se de 425 turmas de 22 escolas públicas de ensino médio com 15.134 alunos matriculados e uma média de 35,6 alunos por turma. A Diretoria Regional de Ensino de São José do Rio Preto forneceu o número de alunos, o turno (diurno e noturno), a série (primeira, segunda e terceira) e a localização (centro e periferia).

\section{Desenho do estudo e amostragem}

Do repertório epidemiológico para abordar a questão do consumo de substâncias psicoativas, os estudos de cortetransversal cobrem satisfatoriamente os objetivos do trabalho. Utilizou-se uma amostragem por conglomerados em único estágio: turmas.

Elaborou-se lista com todas as 425 turmas e as respectivas quantidades de alunos ordenadas em primeiro lugar pelo turno, em segundo pela localização e em terceiro pela série. Por intermédio de sorteio sistemático, 41 turmas foram selecionadas, com a inclusão na amostra de todos os alunos pertencentes a cada uma delas. Três escolas não tiveram salas sorteadas. $\mathrm{O}$ sor- 
teio sistemático proporcionou a estratificação da amostra segundo localização, turno e série.

Maiores detalhes no desenho do estudo e cálculo do tamanho da amostra podem ser encontrados no artigo Prevalência do Uso de Drogas entre Escolares do Ensino Médio de São José do Rio Preto ${ }^{23}$.

\section{Instrumento de coleta de dados}

Para a obtenção das informações sobre o consumo de drogas e outros dados, foi utilizado um questionário anônimo autoaplicado, com 66 questões, a maioria précodificada, tratando-se de caracterização sociodemográfica (sexo, estado civil, faixa etária, trabalho, religião, moradia), aspectos familiares (relacionamento entre os pais, relação com os pais, escolaridade dos pais) e sobre atividades de lazer. O questionário foi desenvolvido para o estudo, baseando-se no instrumento utilizado por Galduróz et al (1997) ${ }^{10}$. Para avaliar o consumo de drogas foram consideradas as seguintes categorias para o uso de substâncias psicoativas, de acordo com a classificação da $\mathrm{OMS}^{25}$ :

- Uso na vida: usou pelo menos uma vez na vida;

- Uso no ano: usou pelo menos uma vez nos 12 meses anteriores à pesquisa;

- Uso no mês: usou pelo menos uma vez nos 30 dias anteriores à pesquisa;

- Uso na semana: usou pelo menos uma vez nos 7 dias anteriores à pesquisa; Realizou-se um pré-teste com a aplicação do questionário em uma turma de alunos e adaptação do material para as dificuldades levantadas. Os questionários foram aplicados nos meses de Outubro e Novembro de 2003, de maneira coletiva nas turmas selecionadas, e mantidos sem identificação. Não havia data marcada para a aplicação, e só participaram da pesquisa os alunos presentes na sala de aula no dia da aplicação do questionário e que entregaram o Termo de Consentimento assinado por responsável. Não houve critérios de exclusão.

\section{Análise dos dados}

Os questionários foram conferidos individualmente para a exclusão daqueles entregues em branco ou claramente não fidedignos (discrepâncias entre respostas), e digitados em um banco de dados no Microsoft Excel 2000®. Responderam ao questionário 1.041 alunos, com 6 exclusões.

A análise estatística foi realizada nos programas Epi Info 2002® e Intercooled Stata $7.0 ®$, considerando desenho amostral por conglomerados com a turma como unidade primária de amostragem (UPA). Não foi considerada para a análise estatística a estratificação em turno, localização e série.

Foram selecionados para as análises os usuários de maconha na vida e no mês, buscando abordar tanto um consumo experimental (uso na vida) como um consumo atual e possivelmente mais freqüente (uso no mês). Foi utilizado o consumo no último mês e não o na última semana por não haver diferença entre as prevalências de uso de maconha no mês e na semana, segundo o Intervalo de Confiança (IC) de $95 \%$ (respectivamente $4,1 \%$ com IC de 2,3 a $5,9 \%$, e $2,9 \%$ com IC de 1,5 a $4,3 \%)^{23}$, obtendo-se um aumento na amostra de 29 alunos para 42 alunos, com maior precisão nos cálculos estatísticos.

As variáveis uso de maconha na vida e uso de maconha no mês foram cruzadas com as outras variáveis selecionadas. A existência de associação nos cruzamentos foi considerada quando o p-valor era inferior a 0,05 .

\section{Ética da Pesquisa}

A pesquisa foi autorizada pelo Comitê de Ética em Pesquisa da Faculdade de Medicina de São José do Rio Preto, sob protocolo número 5561/2002, pela Diretoria Regional de Ensino de São José do Rio Preto e pelos diretores de cada escola. As escolas sorteadas e seus alunos foram convidados a participar da pesquisa, sendo solicitados aos participantes, ou ao res- 
ponsável quando o aluno era menor de idade, assinarem um termo de consentimento livre e esclarecido para a participação na pesquisa. Não houve recusa por parte das escolas sorteadas.

Não há conflito de interesses na realização do estudo.

\section{Resultados}

A partir da aplicação dos questionários nas 41 turmas sorteadas, obteve-se uma amostra de 1.035 alunos. A maioria dos estudantes estava na faixa etária de 16 a 17 anos (56,6\%), seguida pelas faixas de 14 a 15 anos (21,5\%) e 18 a 19 anos (17,7\%). A parcela mais expressiva (67\%) morava com pai e mãe e 19,3\% moravam apenas com a mãe. Em relação à religião, 61,7\% declararam-se católicos, 22,7\% evangélicos/protestantes e 6,8\% sem religião. As distribuições por sexo se equivalem a $48,2 \%$ e
$51,8 \%$, respectivamente para o sexo masculino e feminino ${ }^{23}$. As freqüências para o uso de maconha na vida e no mês foram $12,1 \%$ e $4,1 \%$ respectivamente.

A idade da primeira experiência com maconha foi entre os 14 e os 16 anos, segundo 74,2\% dos alunos, com média de 15 anos de idade (Tabela 1).

Na Tabela 1 encontra-se a prevalência do uso de maconha na vida e no mês relacionada com algumas variáveis. Maiores taxas de consumo na vida e no mês foram encontradas no sexo masculino, no período noturno e no grupo dos que não têm religião ou não praticam sua religião $(\mathrm{p}<0,05)$. Estado civil casado, trabalhar $\mathrm{e}$ não morar com pai e/ou mãe estiveram associados a maiores índices de experimentação da droga, mas não ao uso recente (no mês). Contudo, quando se considerou apenas morar com pai e mãe, essa condição mostrou prevalência inferior para o

Tabela 1 - Idade da primeira experiência com maconha e prevalência do uso de maconha segundo sexo, estado civil, período, trabalho, religião e moradia. SJRP, SP, 2003. N=1035.

Table 1 - Age of the first experience with marijuana and prevalence of marijuana consumption according to gender, marital status, study period, work, religion, and dwelling. São José do Rio Preto, SP, Brazil, 2003.

\begin{tabular}{|c|c|c|c|c|c|c|c|}
\hline & & $\mathrm{n}$ & $\%$ & média & & & \\
\hline Idade da & $10-13$ & $18 / 124$ & 14,5 & & & & \\
\hline primeira & $14-16$ & $92 / 124$ & 74,2 & 15 & & & \\
\hline \multirow[t]{3}{*}{ experiência } & $17-21$ & $14 / 124$ & 11,3 & & & & \\
\hline & & \multicolumn{3}{|c|}{ uso na vida } & \multicolumn{3}{|c|}{ uso no mês } \\
\hline & & $\mathrm{n}$ & $\%$ & p-valor & $\mathrm{n}$ & $\%$ & $\mathrm{p}$-valor \\
\hline \multirow[t]{2}{*}{ sexo } & masculino & $69 / 488$ & 14,1 & 0,0204 & $26 / 486$ & 5,3 & 0,0280 \\
\hline & feminino & $53 / 527$ & 10,1 & & $15 / 525$ & 2,9 & \\
\hline \multirow[t]{2}{*}{ estado civil } & solteiro & $113 / 983$ & 11,5 & 0,0170 & $40 / 979$ & 4,1 & 0,9800 \\
\hline & casado & $7 / 25$ & 28,0 & & $1 / 25$ & 4,0 & \\
\hline \multirow[t]{2}{*}{ período } & diurno & $48 / 618$ & 7,8 & 0,0004 & $15 / 615$ & 2,4 & 0,0058 \\
\hline & noturno & $77 / 407$ & 18,9 & & $29 / 406$ & 7,1 & \\
\hline \multirow[t]{2}{*}{ trabalho } & $\operatorname{sim}$ & $66 / 405$ & 16,3 & 0,0018 & $23 / 404$ & 5,7 & 0,0870 \\
\hline & não & $56 / 610$ & 9,2 & & $18 / 607$ & 3,0 & \\
\hline \multirow[t]{2}{*}{ religião } & pratica & $66 / 770$ & 8,6 & 0,0000 & $18 / 767$ & 2,3 & 0,0002 \\
\hline & $\begin{array}{l}\text { não tem / } \\
\text { não pratica }\end{array}$ & $58 / 250$ & 23,2 & & $23 / 248$ & 9,3 & \\
\hline \multirow[t]{2}{*}{ moradia } & pai e / ou mãe & $99 / 909$ & 10,9 & 0,0091 & $33 / 906$ & 3,6 & $0,1015^{* *}$ \\
\hline & outro* & $23 / 103$ & 22,3 & & 8/102 & 7,8 & \\
\hline
\end{tabular}

* cônjuge/companheiro, outros familiares, amigos, sozinho, república

** Considerando-se apenas morar com pai e mãe, $\mathrm{p}$-valor $=0,0411$ 
consumo de maconha no mês $(\mathrm{p}<0,05)$.

$\mathrm{O}$ consumo de maconha segundo o relacionamento familiar e a escolaridade dos pais encontra-se na Tabela 2. A prevalência de uso na vida nos escolares cujos pais vivem juntos e mantêm um bom relacionamento entre si foi de $8,4 \%$, inferior à prevalência de $17,2 \%$ (p-valor $<0,05$ ) nos escolares em que os pais viviam em outra situação (juntos com relacionamento regular/ruim, separados, pai falecido, mãe falecida, pai e mãe falecidos). A freqüência de consumo no mês não se relacionou significantemente com a situação conjugal $(\mathrm{p}=0,061)$.

Relacionamento ótimo ou bom com o pai esteve associado a menores índices de uso de maconha na vida e no mês, e relacionamento ótimo ou bom com a mãe esteve associado a menor índice de experiência com maconha, mas não com o uso no mês (Tabela 2). Ao considerarmos apenas o relacionamento ótimo com a mãe, este se associou a menores índices de consumo no mês, com $\mathrm{p}<0,01$.

Quanto à escolaridade, a única associação encontrada foi entre a mãe possuir ensino médio completo a ensino superior completo, e maior prevalência de experi- ência com maconha $(14,9 \%$ contra $10,9 \%$ para mãe até ensino médio incompleto, pvalor <0,05).

$\mathrm{Na}$ Tabela 3 encontram-se as atividades de lazer mais comuns entre os escolares em geral, comparando com os estudantes que já fizeram uso de maconha alguma vez na vida. As atividades mais relacionadas àqueles que experimentaram maconha foram $(\mathrm{p}<0,05)$ : sair sem destino certo, ir dançar, freqüentar bares e ficar com namorado(a), enquanto aquelas menos relacionadas foram $(\mathrm{p}<0,05)$ : assistir televisão, sair com a família e ir ao cinema. Com outras atividades não houve diferença significante. Para o consumo no mês, as diferenças se acentuaram, mantendo as significâncias, porém a atividade usar computador/videogame foi menos citada por aqueles que utilizaram maconha no mês (p-valor $<0,05$ ).

$\mathrm{Na}$ Tabela 4, maior prevalência de experiência com maconha foi relacionada com a ingestão de bebida alcoólica semanalmente, e uso de tabaco, com $\mathrm{p}<0,0001$. Dentre os que ingerem bebida alcoólica toda semana, $35,5 \%$ experimentaram maconha, e dentre os que fumam tabaco $35,9 \%$ experimentaram, enquanto para os

Tabela 2 - Aspectos familiares e prevalência do consumo de maconha na vida e no mês, SJRP, SP, 2003. N=1035.

Table 2 - Family aspects and prevalence of marijuana consumption throughout life and in the past month. São José do Rio Preto, SP, Brasil, 2003.

\begin{tabular}{|c|c|c|c|c|c|c|c|}
\hline & & \multicolumn{3}{|c|}{ vida } & \multicolumn{3}{|c|}{ mês } \\
\hline & & $\mathrm{n}$ & $\%$ & p-valor & $\mathrm{n}$ & $\%$ & p-valor \\
\hline \multirow[t]{3}{*}{ Como vivem os pais } & juntos com bom & & & & & & \\
\hline & relacionamento & $51 / 610$ & 8,4 & 0,0001 & $19 / 608$ & 3,1 & 0,0610 \\
\hline & outro* & $69 / 401$ & 17,2 & & $22 / 399$ & 5,5 & \\
\hline \multirow[t]{2}{*}{ Relação pai** } & ótima / boa & $64 / 749$ & 8,5 & 0,0000 & $21 / 746$ & 2,8 & 0,0011 \\
\hline & regular/ruim/péssima & $25 / 116$ & 21,6 & & $10 / 116$ & 8,6 & \\
\hline \multirow[t]{2}{*}{ Relação mãe** } & ótima / boa & $102 / 915$ & 11,1 & 0,0004 & $34 / 911$ & 3,7 & $0,2501 * * *$ \\
\hline & regular/ruim/péssima & $16 / 65$ & 24,6 & & $4 / 65$ & 6,2 & \\
\hline \multirow[t]{2}{*}{ Escolaridade pai } & até ensino médio incompleto & $57 / 555$ & 10,3 & 0,2102 & $24 / 553$ & 4,3 & 0,0793 \\
\hline & ensino médio completo a superior & $39 / 300$ & 13,0 & & $6 / 299$ & 2,0 & \\
\hline \multirow[t]{2}{*}{ Escolaridade mãe } & até ensino médio incompleto & $58 / 558$ & 10,4 & 0,0216 & $22 / 555$ & 4,0 & 0,6487 \\
\hline & ensino médio completo a superior & $52 / 348$ & 14,9 & & $12 / 347$ & 3,5 & \\
\hline
\end{tabular}

* Juntos com relacionamento regular/ruim, separados, pai e/ou mãe falecido (s)

** Exclui não convive

*** p-valor $=0,0026$ quando se considera apenas a relação ótima com a mãe 
Tabela 3 - Atividades de lazer citadas na população geral e entre aqueles que experimentaram maconha. SJRP, SP, 2003.

Table 3 - Leisure activities mentioned in the general population and among those who experimented marijuana. São José do Rio Preto, SP, Brazil, 2003.

\begin{tabular}{lccccc}
\hline & população geral & \multicolumn{3}{c}{ uso na vida } \\
& $\mathrm{n}$ & $\%$ & $\mathrm{n}$ & $\%$ & p-valor* \\
\hline Freqüentar clube & 280 & 27,2 & 31 & 24,8 & 0,5020 \\
Sair com amigos & 703 & 68,2 & 89 & 71,2 & 0,3970 \\
Praticar esporte & 431 & 41,8 & 53 & 42,4 & 0,8900 \\
Assistir televisão & 614 & 59,6 & 62 & 49,6 & 0,0260 \\
Sair com a família & 433 & 42,0 & 18 & 14,4 & 0,0000 \\
Sair sem destino certo & 147 & 14,3 & 36 & 28,8 & 0,0000 \\
Ir ao cinema & 428 & 41,5 & 33 & 26,4 & 0,0026 \\
Ir dançar & 250 & 24,2 & 45 & 36,0 & 0,0002 \\
Freqüentar bares & 136 & 13,2 & 39 & 31,2 & 0,0000 \\
Ficar com namorado(a) & 399 & 38,7 & 63 & 50,4 & 0,0080 \\
Usar computador (internet) / videogame & 339 & 32,9 & 37 & 29,6 & $0,3376^{*}$ \\
Outros & 94 & 9,1 & 14 & 11,2 & 0,3063 \\
\hline Total & 1031 & \multicolumn{5}{c}{125} & \\
\hline
\end{tabular}

* No mês, a significância se manteve, contudo para usar computador (internet) / videogame a porcentagem foi 19\% e o pvalor 0,0424

Tabela 4 - Experiência com maconha na ingestão de bebida alcoólica semanal ou uso de tabaco. SJRP, SP, 2003. N=1035.

Table 4 - Marijuana experience among those who drink alcohol weekly and those that use tobacco. São José do Rio Preto, SP, Brazil, 2003.

\begin{tabular}{|c|c|c|c|c|c|}
\hline \multirow{4}{*}{$\begin{array}{l}\text { experimentou } \\
\text { maconha } \\
\text { sim }\end{array}$} & \multicolumn{4}{|c|}{ ingere bebida alcoólica toda semana } & \multirow[t]{3}{*}{ p-valor } \\
\hline & \multicolumn{2}{|c|}{ não } & \multicolumn{2}{|c|}{$\operatorname{sim}$} & \\
\hline & $\mathrm{n}$ & $\%$ & $\mathrm{n}$ & $\%$ & \\
\hline & $70 / 868$ & 8,1 & $54 / 152$ & 35,5 & $<0,0001$ \\
\hline & \multicolumn{4}{|c|}{ fumou tabaco uma vez na vida } & p-valor \\
\hline & \multicolumn{2}{|c|}{ não } & \multicolumn{2}{|c|}{$\operatorname{sim}$} & \\
\hline & $\mathrm{n}$ & $\%$ & $\mathrm{n}$ & $\%$ & \\
\hline $\operatorname{sim}$ & $21 / 732$ & 2,9 & $104 / 290$ & 35,9 & $<0,0001$ \\
\hline
\end{tabular}

que não apresentaram essa exposição os índices ficaram em $8,1 \%$ e $2,9 \%$ de experiência, respectivamente.

$\mathrm{Na}$ Tabela 5, temos a prevalência do consumo de cocaína, crack, anfetamínico, alucinógeno, álcool e tabaco segundo o consumo de maconha na vida. A experiência com maconha esteve relacionada ao maior consumo de todas essas drogas $(p<0,0001)$. De 34 escolares que experimentaram cocaína, apenas 5 não experimentaram maconha, e os 14 experimen- tadores de crack usaram maconha. Contudo, devido à característica do estudo em corte transversal, não é possível estabelecer a temporalidade dos eventos.

\section{Discussão}

O estudo apresenta limitações quanto à generalização dos resultados para todos os alunos de ensino médio do Brasil e para os adolescentes em geral, pois trata de alunos que freqüentam escolas públicas em 
Tabela 5 - Consumo de outras drogas relacionado a ter ou não experimentado maconha. SJRP, SP, 2003. $\mathrm{N}=1035$.

Table 5 - Relation between consumption of others drugs and having experimented or not marijuana. São José do Rio Preto, SP, 2003.

\begin{tabular}{|c|c|c|c|c|c|c|}
\hline \multirow[b]{3}{*}{ Utilizou } & \multicolumn{4}{|c|}{ Experimentou maconha } & \multirow{3}{*}{$\begin{array}{c}\text { População } \\
\text { geral* } \\
\%\end{array}$} & \multirow[t]{3}{*}{$\mathrm{p}$-valor } \\
\hline & \multicolumn{2}{|c|}{ não } & \multicolumn{2}{|c|}{$\operatorname{sim}$} & & \\
\hline & $\mathrm{n}$ & $\%$ & $\mathrm{n}$ & $\%$ & & \\
\hline cocaína & $5 / 895$ & 0,6 & $29 / 125$ & 23,2 & 3,3 & $<0,0001$ \\
\hline crack & $0 / 891$ & 0,0 & $14 / 124$ & 11,3 & 1,4 & $<0,0001$ \\
\hline anfetamínico & $17 / 887$ & 1,9 & $21 / 123$ & 17,1 & 3,7 & $<0,0001$ \\
\hline alucinógeno & $10 / 891$ & 1,1 & $22 / 122$ & 18,0 & 3,1 & $<0,0001$ \\
\hline álcool** & $96 / 896$ & 10,9 & $54 / 124$ & 43,5 & 15,1 & $<0,0001$ \\
\hline tabaco & $186 / 897$ & 20,7 & $104 / 125$ & 83,2 & 28,7 & $<0,0001$ \\
\hline
\end{tabular}

* Prevalência do uso de drogas entre escolares do ensino médio de SJRP - SP ${ }^{34}$

** Consumir ao menos 1 vez por semana

uma localidade específica. Nos adolescentes que não freqüentam a escola, a apresentação e a freqüência de consumo de drogas tendem a possuir outro perfil ${ }^{1,4,6}$.

Devido à realização da coleta de dados nas classes em dia único e incluir apenas os alunos presentes no momento, o resultado para o uso de drogas pode estar subestimado quanto à freqüência de uso e consumo de drogas mais pesadas, uma vez que os alunos cronicamente faltosos consomem drogas com maior freqüência e utilizam drogas mais pesadas ${ }^{1,4,6,9}$.

O consumo de maconha apresentou-se alto em São José do Rio Preto, quando comparado com o Brasil em geral ${ }^{3,10,23}$; contudo, continua entre os índices já encontrados em outras cidades brasileiras ${ }^{3,9,10,19,23}$. A idade da primeira experiência (Tabela 1) foi semelhante à encontrada em outros estudos, nos quais as médias variaram entre 14 e 17 anos de idade i,9,12,19. $^{3}$.

Sexo masculino e período de estudo noturno são freqüentemente associados a um maior consumo de maconha e drogas ilícitas em geral, com exceção para o uso de medicamentos ${ }^{9,11,12,19,21,23}$, de acordo com os resultados encontrados nesse estudo (Tabela 1).

Uma convivência familiar harmoniosa é relatada na literatura como fator associado ao menor consumo de drogas ${ }^{5,14,22,26}$. Como visto na Tabela 2, os pais viverem juntos com bom relacionamento, e relação ótima ou boa com pai ou mãe estão relacionados a menores índices de experiência e uso de maconha no último mês, enquanto uma relação regular, ruim ou péssima associa-se a um maior consumo da droga. Não morar com pai e/ou mãe, que também esteve relacionado a um maior uso de maconha, pode fazer parte de um relacionamento familiar ruim ${ }^{26}$.

A religiosidade é citada na literatura como protetora para a experiência com maconha e outras drogas ${ }^{26,27}$, e no presente estudo a prática da religião esteve associada a menores índices de experiência e uso mais freqüente de maconha. Por outro lado, estar casado e trabalhar estão associados a maiores índices de experimentação de maconha.

Por se tratar de estudo com escolares do ensino médio, cerca de $78 \%$ menores de idade $^{23}$, no período mais comum de início do consumo de drogas, é possível que as associações da experiência com maconha e período noturno, estado civil casado e trabalhar ocorram devido à confusão com a idade. Visando avaliar essa hipótese, foram calculadas as médias de idade dos escolares segundo o uso de maconha na vida, período escolar, estado civil e trabalho (Tabela 6). Tanto os alunos que experimentaram maconha como os do período noturno, os casados e os que trabalham, têm idade 
Tabela 6 - Médias de idade segundo o uso de maconha, período escolar, estado civil e trabalho. SJRP, SP, 2003. N=1035.

Table 6 - Age averages according to marijuana experience, study period, marital status and work. São José do Rio Preto, SP, Brazil, 2003.

\begin{tabular}{lccc}
\hline & $\mathrm{N}$ & Média & p-valor \\
\hline Experimentou maconha & $118 / 1001$ & 17,3 & 0,007 \\
Não experimentou & $883 / 1001$ & 16,6 & \\
\hline Período diurno & $613 / 1010$ & 16,2 & $<0,001$ \\
Período noturno & $397 / 1010$ & 17,5 & $<0,001$ \\
\hline Casado & $25 / 1002$ & 19,4 & \\
Solteiro & $977 / 1002$ & 16,7 & $<0,001$ \\
\hline Trabalha & $403 / 1009$ & 17,2 & \\
Não trabalha & $606 / 1009$ & 16,4 & \\
\hline
\end{tabular}

significantemente superior à dos respectivos escolares em outra situação, indicando ser válida a hipótese de confusão com a idade para essas variáveis.

Na Tabela 2 é observada a correlação entre a mãe possuir ensino médio completo ou ensino superior e um maior índice de experiência com maconha em relação àqueles com mãe de menor escolaridade. Esse dado pode significar disponibilidade financeira, associada a um maior consumo de drogas ilícitas em alguns estu$\operatorname{dos}^{12,13,21}$, menor contato com a mãe, resultando em um pior relacionamento familiar, já discutido, ou dever-se a confusão com outras variáveis, esta devido à não correlação entre a experiência com maconha e a escolaridade do pai, ou uso no mês e escolaridade da mãe.

Quando foram listadas as atividades de lazer mais comuns entre os escolares no geral e entre aqueles que já experimentaram maconha (Tabela 3), houve destaque para o relacionamento familiar. Enquanto em geral $42 \%$ referiram sair com a família, entre os que experimentaram maconha $14,4 \%$ referiram essa atividade $(\mathrm{p}<0,0001)$. Menos usuários na vida referiram assistir televisão e ir ao cinema, atividades que podem estar relacionadas a ambiente familiar (ver televisão), menor disponibilidade financeira e ambiente público sem possibilidade de consumir a droga (ir ao cine- ma). Contudo esse poderia ser apenas o perfil do experimentador de maconha, sem influência na experiência com a droga.

A Tabela 4 apresenta a significante associação do uso de álcool toda semana e de tabaco com a experiência com maconha, relatada em outros estudos ${ }^{14,17,22}$. O uso dessas substâncias poderia significar uma primeira fase antes do início do consumo de maconha ${ }^{17}$, indicando uma predisposição nos usuários pesados de drogas lícitas para a experiência com outras drogas.

A experiência com maconha é relatada como uma importante fase antes do consumo de drogas ilícitas mais pesadas, como a cocaína, o crack e alucinóge$\operatorname{nos}^{14,17,22}$. Nesse estudo, maior prevalência da experiência com cocaína, crack, anfetamínicos e alucinógenos foi encontrada naqueles que também experimentaram maconha (Tabela 5, p<0,0001). Apesar de não sabermos a temporalidade dessas associações, o consumo de maconha ocorre geralmente em idades mais precoces que o das outras drogas citadas ${ }^{1,2,3,9,12,19}$. Sanchez \& Nappo (2002) relataram o consumo de maconha antecedendo o de cocaína, alucinógenos e crack em 30 de 31 usuários ou ex-usuários de crack.

A presença de álcool e tabaco na Tabela 5 indica também o maior consumo de drogas lícitas entre aqueles que já experimentaram maconha, dado importante 
pelo fato de o consumo destas drogas ser, epidemiologicamente, mais prejudicial à saúde e à sociedade.

\section{Conclusão}

O consumo de maconha relaciona-se com muitas variáveis, inclusive cultura e situação socioeconômica de cada localidade. Portanto, na avaliação de fatores de risco e protetores, deve-se ficar atento à confusão entre as diversas variáveis envolvidas.

Uma família harmoniosa e a religiosidade mostraram-se possíveis fatores de proteção ao consumo de maconha. Os adolescentes que experimentaram maconha tendem a possuir atividades de lazer com diferenças quanto aos que não experimen- taram, possivelmente indicando perfis psicológicos, econômicos e/ou sociais diversos. O consumo de outras drogas ilícitas e de drogas lícitas foi mais comum entre aqueles que experimentaram maconha, fortalecendo a idéia da progressão no consumo de drogas, das lícitas para a maconha, e desta para outras drogas ilícitas.

O estudo caracterizou os usuários de maconha, servindo de auxílio a futuras pesquisas epidemiológicas sobre o abuso de drogas. Ao considerar os aspectos relacionados ao consumo de maconha, programas de prevenção e recuperação de jovens envolvidos com essa e outras drogas podem ser mais eficazes, visando minimizar os danos físicos e psíquicos ao indivíduo, assim como os prejuízos à sociedade.

\section{Referências}

1. Tavares BF, Béria JU, Lima MS. Prevalência do uso de drogas e desempenho escolar entre adolescentes. Rev Saúde Pública 2001;35:150-8.

2. Baus S, Kupek E, Pries M. Prevalência e fatores de risco relacionados ao uso de drogas entre escolares. Rev Saúde Pública 2002, 36: 40-6.

3. Carlini EA, Galduróz JC, Noto AR, Nappo AS. I Levantamento Domiciliar Sobre o Uso de Drogas Psicotrópicas no Brasil. São Paulo: Centro Brasileiro de Informações sobre Drogas Psicotrópicas, Departamento de Psicobiologia, Escola Paulista de Medicina, Universidade Federal de São Paulo; 2001.

4. Soldera M, Dalgalarrondo P, Corrêa Filho HR, Silva CAM. Uso de drogas psicotrópicas por estudantes: prevalência e fatores sociais associados. Rev Saúde Pública 2004; 38 : 277-83.

5. De Micheli D, Formigoni ML. Drug use by Brazilian students: associations with family, psychosocial, health, demographic and behavioral characteristics. Addiction 2004; 99:570-8.

6. Medina-Mora ME, Cravioto P, Villatoro J, Fleiz C, GalvánCastillo F, Tapia-Conyer R. Consumo de drogas entre adolescentes: resultados de la Encuesta Nacional de Adicciones, 1998. Salud Pública Mex 2003; 45 S1: S16-25.

7. Tiba I. A Maconha e o Jovem - Família, Escola e Sociedade. São Paulo: Agora; 1989.

8. Colli AS, Saito MI. Adolescência. In: Marcondes E (org.). Pediatria Básica. São Paulo: Editora Sarvier; 1994. p. 53969.
9. Guimarães JL, Godinho PH, Cruz R, Kappann JI, Tosta Jr LA. Consumo de drogas psicoativas por adolescentes escolares de Assis, SP. Rev Saúde Pública 2004; 38: 130-2.

10. Galduróz JCF, Noto AR, Carlini E. IV Levantamento sobre o uso de drogas entre estudantes do $1^{\circ}$ e $2^{\circ}$ graus em 10 capitais brasileiras. São Paulo: Centro Brasileiro de Informações sobre Drogas Psicotrópicas, Departamento de Psicobiologia, Escola Paulista de Medicina, Universidade Federal de São Paulo; 1997.

11. Compton WM, Grant BF, Colliver JD, Glantz MD, Stinson FS. Prevalence of Marijuana Use Disorders in the United States: 1991-1992 and 2001-2002. JAMA 2004; 291 (17): 2114-22.

12. Fuentealba R, Cumsille F, Araneda JC, Molina C. Consumo de drogas lícitas e ilícitas en Chile: resultados del estudio de 1998 y comparación com los estudios de 1994 y 1996. Rev Panam Salud Pública 2000; 7(2): 79-87.

13. Dormitzer CM, Gonzalez GB, Penna M, Bejarano J, Obando P, Sanchez M, et al. The PACARDO research project: youthful drug involvement in Central America and the Dominican Republic. Rev Panam Salud Pública 2004; 15(6): 400-16.

14. Ljubotina D, Galic J, Jukic V. Prevalence and risk factors of substance use among urban adolescents: questionnaire study. Croatian Med J 2004; 45(1): 88-98.

15. Rekve R, Lindbaek M. Drug abuse among high school students in Hamar in 1999. Tidsskrift for Norsk Laegeforening 2002; 122(25): 2448-51. 
16. Rebello S, Monteiro S, Vargas E. A visão de escolares sobre drogas no uso de um jogo educativo. Interface Comunic Saúde Educ 2001; 5(8): 75-88.

17. Sanchez ZM, Nappo SA. Seqüência de drogas consumidas por usuários de crack e fatores interferentes. Rev Saúde Pública 2002; 36(4): 420-30.

18. Coutinho MPL, Araújo LF, Gontiès B. Uso da maconha e suas representações sociais: estudo comparativo entre universitários. Psicologia em Estudo 2004; 9(3): 469-77.

19. Souza DPO, Martins DTO. O perfil epidemiológico do uso de drogas entre estudantes de $1^{\circ} \mathrm{e} 2^{\circ}$ graus da rede estadual de ensino de Cuiabá, Brasil, 1995. Cad Saúde Pública 1998; 14: 391-400.

20. Muza GM, Bettiol H, Muccillo G, Barlieri MA. Consumo de substâncias psicoativas por adolescentes escolares de Ribeirão Preto, SP. II - Distribuição do consumo por classes sociais. Rev Saúde Pública 1997; 31: 163-70.

21. Carlini-Cotrim B, Gazal-Carvalho C, Gouveia N. Comportamentos de saúde entre jovens estudantes das redes pública e privada da área metropolitana do Estado de São Paulo. Rev Saúde Pública 2000; 34(6): 636-45.

22. Windle M, Mason WA. General and Specific Predictors of Behavioral and Emotional Problems Among Adolescents. J Emot Behav Dis 2004; 12(1): 49-62.
23. Silva EF, Pavani RAB, Moraes MS, Chiaravalloti Neto F. Prevalência do uso de drogas entre escolares do ensino médio do município de São José do Rio Preto, São Paulo, Brasil. Cad Saúde Pública 2006; 22(6): 1151-8.

24. DATASUS. Informações demográficas. Disponível em http://www.tabnet.datasus.gov.br/cgi/ tabcgi. Acessado em 10 de novembro de 2004.

25. World Health Organization. Nomenclature and Classification of Drug and Alcohol - related problems: a WHO memorandum. Bull World Health Organ 1981; 59: 225-45.

26. Sanchez ZM, Oliveira LG, Nappo AS. Fatores protetores de adolescentes contra o uso de drogas com ênfase na religiosidade. Ciência \& Saúde Coletiva 2004; 9(1): 43-55.

27. Miller L, Davis M, Greenwald S. Religiosity and substance use and abuse among adolescents in the National Comorbidity Survey. J Am Acad Child Adolesc Psychiatry 2000; 39(9): 1190-7.

Recebido em: 22/09/06 Versão final reapresentada em: 25/04/07 Aprovado em: 04/05/07 